\title{
A NEXT GENERATION SCALAR INTENSITY MEASURE FOR ANALYTICAL VULNERABILITY STUDIES
}

\author{
Athanasia K. Kazantzi ${ }^{1}$ and Dimitrios Vamvatsikos ${ }^{1}$ \\ ${ }^{1}$ National Technical University of Athens \\ 9 Heroon Polytechneiou, 15780 Athens, \\ \{kazantzi,divamva\}@mail.ntua.gr
}

Keywords: Intensity Measure, Vulnerability, Significant Duration, Collapse Capacity.

\begin{abstract}
To assess the seismic performance of a structural system within an analytical context, we need, among others, to specify a ground motion Intensity Measure (IM). The wary IM selection is undoubtedly an important step towards the successful implementation of a risk assessment, since insufficient and/or inefficient IMs can induce unwanted bias and variance in the vulnerability estimates. Supplementary issues related to practicality, necessitate the use of IMs for which ground motion prediction relationships exist, such as the elastic response spectral values (i.e. acceleration, velocity and displacement). Several past studies suggested as an improvement the use of IMs defined as the geometric mean of spectral acceleration values computed over a period range. The latter range may span between periods that are below, at or above the fundamental one. Some of these choices were proven to significantly improve both efficiency and sufficiency of the IM compared to more commonly used counterparts.
\end{abstract}

This study investigates the efficiency and sufficiency of a newly developed scalar IM that combines the geometric mean IM concept with the significant duration of the ground motions. Improving the geometric mean IMs via including the significant duration of the ground motions, was driven by recent findings suggesting there is a strong tie between the collapse capacity of a structure and the ground motion duration. Hence, the performance of the proposed next generation IM is addressed in detail by means of comparisons and statistical significance tests. The testing is performed at specific levels of local engineering demand parameters that are closely related to losses, using a testbed capacity-designed steel moment-resisting frame. It was demonstrated that ground motion duration is closely related to the collapse capacity whereas its effect at lower demand levels is insignificant. Hence, the proposed IM may be employed to improve the estimates in collapse assessment studies. Nevertheless, at least for steel moment-resisting frame buildings that exhibit moderate cyclic degradation rates and sustain most losses prior to the global collapse state, the significant duration is anticipated to only minimally affect the evaluated vulnerability and consequently may be disregarded. 


\section{INTRODUCTION}

To perform an analytical seismic vulnerability assessment of a structural system, we need, among others, to specify a ground motion Intensity Measure (IM). An IM is actually an interface variable that efficiently separates the seismology and the structural engineering domains. This distinction is manifested in that the seismologists could independently estimate the IM's statistical properties via a probabilistic seismic hazard analysis [1], while the engineers can economize by assessing structural responses, vulnerability and losses conditioned solely on the IM level, rather than on the basis of the several seismological parameters (e.g. magnitude, distance etc). To achieve this desirable decoupling, the IM needs to be (a) practical, (b) efficient and (c) sufficient with respect to the underlying characteristics of the site and source [2].

Practicality necessitates the use of IMs for which Ground Motion Prediction Equations (GMPEs), also known as attenuation relationships, are available. This generally restricts us to the realm of peak ground acceleration/velocity/displacement and pseudo spectral acceleration values. Efficiency means that structural response, measured by appropriate Engineering Demand Parameters (EDPs), at any given level of the IM, should exhibit a low record-to-record variability. This enables the evaluation of the conditional EDP distribution with a small number of time-history analyses without incurring considerable estimate errors. Finally, the sufficiency requirement stipulates that the IM can "cover" the effect of any important seismological parameter, thus removing any bias from considering e.g. ground motions of different magnitudes, distances, fault rupture mechanisms, or epsilons (see [3]).

On account of the above, several past studies suggested as an improvement the use of IMs defined as the geometric mean of spectral acceleration values computed over a period range. For instance, Cordova et al. [4] suggested the use of the geometric mean of two $S_{a}$ components evaluated at two period levels, these being the fundamental period $\left(T_{1}\right)$ and a period that is two times the fundamental one $\left(2 T_{1}\right)$. The latter period level was introduced at the IM estimation so as to account for the period elongation associated with the structural damage. This choice was proven to significantly improve both the efficiency and the sufficiency of the estimation, compared to $S_{a}(T)$. It also remains practical, as a GMPE for $S_{a g m}\left(T_{i}\right)$ is easily estimated from existing $S_{a}(T)$ GMPEs, given the correlation of spectral ordinates [4]. In a similar track, Tsantaki \& Adam [5] showed that the improvement achieved over the resulted recordto-record variability at collapse, by means of adopting a geometric mean of spectral accelerations, may be further increased by espousing an enhanced period range. For the latter, they proposed a simple analytical expression that links the initial period $T_{1}$ to an elongated period and illustrated that the geometric mean of the spectral accelerations evaluated across that period band, leads to a notable reduction in the seismic collapse capacity dispersion. An additional scalar IM based on $S_{a}\left(T_{1}\right)$ and a parameter $N_{\mathrm{p}}$ that accounts for the spectral shape in a period range, was proposed by Bojorquez \& Iervolino [6] and was found to have good efficiency.

Even more recently, Kazantzi \& Vamvatsikos ([7], [8]) demonstrated that an efficient and sufficient IM for a class of buildings may be attained by specifying an appropriate period range that includes periods above (to account for the period elongation due to structural damage), at and below (to account for the contribution of higher modes) the class-average firstmode period and using the geometric mean of the spectral accelerations evaluated at these periods. The satisfactory performance of the proposed IM was verified across the entire practical range of peak floor acceleration (PFA) and interstory drift ratio (IDR) values at every floor and story, respectively, for building classes that involved both low and high-rise structures. On that premise, and considering the recent findings suggesting the ground motion duration to affect the collapse capacity of both non ductile and ductile structures [9], we will propose in 
this study a new scalar IM that combines the geometric mean IM concept with the significant duration property of the ground motions. The testbed for the present study will be a single contemporary capacity-designed midrise steel moment-resisting frame (MRF) [10]. Nevertheless, it is believed the results being applicable to collapse vulnerability studies that involve either higher numbers of stories or even a class of buildings, but this is up to upcoming ongoing research to prove.

\section{SIGNIFICANT DURATION}

As discussed in the preceding section, an efficient IM, is one for which the structural response, measured by an appropriate EDP at any given level of intensity, yields a low recordto-record variability. On the other hand, a sufficient IM, renders the structural response at a given level of IM insensitive to seismological parameters, such as the magnitude $\left(M_{w}\right)$ and the source-to-site distance $(R)$. The significant duration of the ground motion is actually a function of the magnitude [11] and hence its effect may be considered masked when using a perfectly sufficient IM. Nevertheless, since the latter could only exist theoretically, the ground motion duration effect on the structural response and/or the collapse risk is likely to be nonnegligible. To this end, such field has attracted some research efforts in recent years, which have so far concluded that ground motions with larger durations do not necessarily result in larger peak drift demands [12] but they might trigger a negative correlation with the collapse capacity, more likely due to the higher hysteretic energy demands imposed to the structural system [9].

The term significant or strong motion duration refers, in this study, to the time interval where $5 \%$ and $75 \%$ of the ground motion Arias Intensity (AI) has been recorded [13]. This time interval is denoted as $T_{5-75 \%}\left(=T_{75 \%}-T_{5 \%}\right)$ whereas, the AI property may be calculated using the following equation,

$$
A I=\frac{\pi}{2 g} \int_{0}^{T_{r}} a^{2}(t) d t
$$

where, $a(t)$ is the acceleration history over time in units of $g, T_{r}$ is the total recorded time of the accelerogram and $g$ is the acceleration of gravity.

\section{DEFINITION OF THE NEW SCALAR IM}

In previous studies undertaken by the authors ([7], [8]) it was demonstrated that a geometric mean IM which uses five periods, $S_{a g m}\left(T_{i}\right)$, ranging from the second-mode $\left(T_{2}\right)$ to twice the first-mode period $\left(2 \cdot T_{1}\right)$, performs satisfactorily, efficient and sufficient-wise, for both low and high-rise buildings. Despite its apparent advances compared to other commonly used spectral based IMs, this IM still disregards the potential correlation of the collapse risk to the significant ground motion duration, which was recently found to have a non-negligible effect, especially in the case of ductile structures [9]. To deal with this limitation as well as to explore its potential consequences, we introduce a new definition for a scalar IM that combines the $S_{a g m}\left(T_{i}\right)$ with the significant duration property, $T_{5-75 \%}$. The newly proposed IM, denoted in this study as $\operatorname{IM}\left(T_{5-75 \%}\right)$ maintains practicality and predictability, since both of its terms are readily available by means of existing GMPEs. Nevertheless, its ability to relate more effectively with the structural response and collapse capacity will be thoroughly investigated by means of a testbed application. The $I M\left(T_{5-75 \%}\right)$ may be evaluated using the following formula,

$$
\operatorname{IM}\left(T_{5-75 \%}\right)=\left(T_{5-75 \%}\right)^{k} \cdot S_{\text {agm }}\left(T_{i}\right)
$$


where, $k$ is a weight factor that needs to be determined via calibration studies and $S_{a g m}\left(T_{i}\right)$ is defined as,

$$
S_{a g m}\left(T_{i}\right)=\sqrt[5]{S_{a}\left(T_{2}\right) \cdot S_{a}\left(\min \left[\left(T_{2}+T_{1}\right) / 2,1.5 \cdot T_{2}\right]\right) \cdot S_{a}\left(T_{1}\right) \cdot S_{a}\left(1.5 \cdot T_{1}\right) \cdot S_{a}\left(2 \cdot T_{1}\right)}
$$

The effectiveness of the new scalar $\operatorname{IM}\left(T_{5-75 \%}\right)$, will be tested against three IMs, namely $S_{a}\left(T_{1}\right), S_{a}(1 \mathrm{sec})$ and the $S_{a g m}\left(T_{i}\right)$ choice as this is defined in Equation 3.

\section{TESTBED APPLICATION}

The testbed application of the present study is a capacity-designed steel MRF building. The building consists of four stories, the first being $4.6 \mathrm{~m}$ high and the ones above $3.7 \mathrm{~m}$. It was designed as an office building to 2003 IBC and AISC provisions for the Los Angeles area and it has a rectangular floor plan consisting of 3 bays at $9.1 \mathrm{~m}$ in the North-South direction and 4 bays at $9.1 \mathrm{~m}$ in the East-West direction. Our focus will be the East-West framing, in which only the two middle bays are moment-resisting. The columns of the moment-resisting bays were assumed to be fixed at their bases, whereas they are also spliced at the mid-height of the third story. The beams were designed as reduced sections (RBS) with their 'dogbone' geometries detailed according to FEMA 350 [15]. The building's seismic performance was evaluated using a 2D analytical model with elastic elements in OpenSees [16] were plastic hinge formation (point plasticity) was allowed at column ends as well as at the 'dogbone' location for beams. $\mathrm{P}-\Delta$ effects were included using a first-order treatment of geometric nonlinearity. In addition, a leaning column was added to account for the destabilizing effect of the gravity frame loads without axially stressing the lateral load resisting columns.

The empirical relationships derived from experimental data and recently proposed by Lignos \& Krawinkler [17] are used to model the cyclic behavior of steel components via parameters that determine the pre- and post-capping plastic rotation, the cyclic deterioration in flexural strength and stiffness, the effective yield strength and the post-yield strength ratio of steel components subjected to cyclic loading. The first two vibration periods of the analyzed frame were found to be $1.33 \mathrm{~s}$ and $0.40 \mathrm{~s}$, whereas $2 \%$ Rayleigh damping was assumed at the first and third-mode of vibration. Figure 1 depicts a 2-D idealization of the East-West MRF along with the beam and column section sizes. A detailed description of the MRF geometry, design and modeling can be found in Lignos et al. [18] and Kazantzi et al. [10].

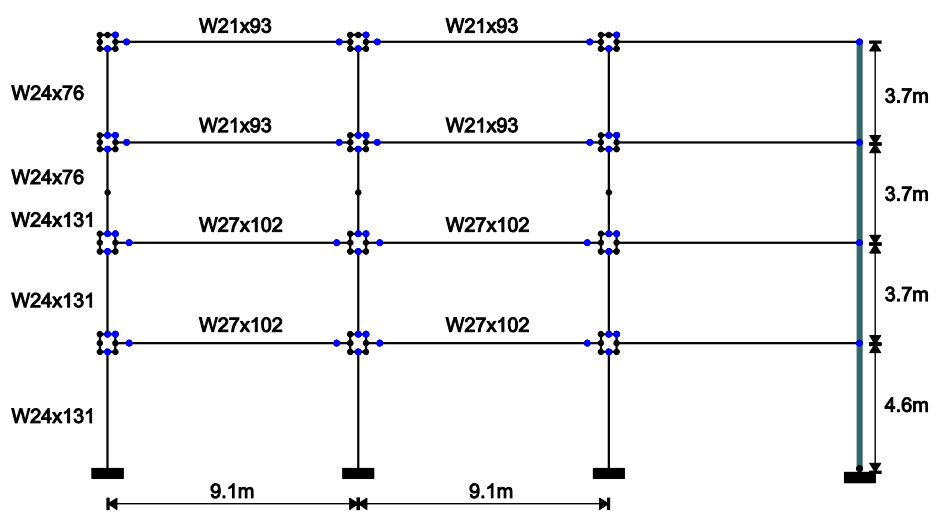

Figure 1: 2D model idealization with leaning column of the analyzed East-West MRF. 


\section{INCREMENTAL DYNAMIC ANALYSIS AND GROUND MOTIONS}

For assessing the seismic performance of the model steel MRF structure, Incremental Dynamic analysis (IDA) was employed [19]. IDA is a powerful tool of structural analysis that involves performing a series of nonlinear time-history analyses for a suite of ground motion records, the latter scaled at increasing intensity levels. To define the IDA curves, two scalars are needed, these being an IM to represent the severity of the seismic input and an EDP to monitor the structural response.

For the needs of this study we have analyzed the testbed MRF under a ground motion set that consists of 76 records. The set contains 68 natural ground motions and 8 simulated ones [21], of which 39 are categorized by Raghunandan \& Liel [9] as short duration records, on the basis of having a significant duration $T_{5-95 \%}<35 \mathrm{~s}$, whereas the remaining 37 were characterized as long duration records, on the basis of having a significant duration $T_{5-95 \%}>35 \mathrm{~s}$. The record set contains ground motions of $M_{w} 4.8$ or above, with a maximum of eight records selected from a single earthquake event. The natural records were obtained from the PEER NGA database [20], the COSMOS Virtual Data Center [22] and the USGS National StrongMotion Project [23] whereas, the simulated ones from the Caltech Virtual Shaker [21]. Table 1 summarizes the main properties of the considered record set. Further details with respect to this set may be found in [9].

\section{IM COMPARISON STUDY}

The efficiency and sufficiency of the newly defined $I M\left(T_{5-75 \%}\right)$, which explicitly accounts for the significant duration of the ground motions, was tested against the three IMs defined in Section 3 (i.e. $S_{a}\left(T_{1}\right), S_{a}(1 \mathrm{sec})$ and $\left.S_{a g m}\left(T_{i}\right)\right)$ across the entire structural response range, i.e. from elasticity up to global collapse. The response is monitored by means of two structural response measures, these being the IDR and the PFA. The adopted methodology for undertaking the comparison between the various considered IMs, is novel in that, contrary to past similar studies that exist in the literature (e.g. [3], [24]), (a) it is performed on a IM given EDP (IM|EDP) basis and (b) it employs all IDR and PFA values at each story or floor, respectively, along with the overall maximum drift quantities. The first deviation from the standard practice has the apparent advantage of allowing a detailed point-wise assessment of efficiency and sufficiency that can reach all the way up to global collapse. By contrast, past studies which were performed on an EDP|IM basis were forced to stay away from the collapse state, since in this region EDP becomes either infinite or undefined. The second deviation point yields useful output for selecting an appropriate IM for loss assessment studies, in which case local rather than overall maximum quantities are considered. Hence, in the present study, each IM will be tested for the 4-story MRF against 11 EDPs: One IDR per story (4 total), one PFA per floor (5 total to include the ground level) plus the overall maximum interstory and roof drift. The latter two may not be used per se in vulnerability calculations, yet they often appear in fragility estimates used in simpler methodologies and collapse risk assessment studies and, thus should not be discounted.

Regarding the weight factor $k$ that appears in the definition of the $\operatorname{IM}\left(T_{5-75 \%}\right)$, calibration studies revealed that a value of 0.2 produces results of satisfactory accuracy. The factor $k$ is likely to be correlated with the cyclic degradation rate of the analyzed MRF but to thoroughly explore that relation is out of the scope of the present study. Nevertheless, in view of this intuition, the presented findings are believed to be valid at least for modern steel MRFs whose structural members experience, in a mean sense, similar cyclic degradation rates. 


\begin{tabular}{|c|c|c|c|c|c|c|c|}
\hline Year & Earthquake & $M_{w}$ & Epis. dist. (km) & NEHRP soil type & pga (g) & $T_{5-95 \%}(\mathrm{~s})$ & $T_{5-75 \%}(\mathrm{~s})$ \\
\hline 1980 & Mammoth Lakes & 4.8 & 1.1 & $\mathrm{D}$ & 0.53 & 1.1 & 0.3 \\
\hline 1935 & Helena, Montana & 6 & 6.3 & $\mathrm{C}$ & 0.15 & 2.2 & 1.3 \\
\hline 1980 & Mammoth Lakes & 5.7 & 2.8 & $\mathrm{D}$ & 0.43 & 3.5 & 2.4 \\
\hline 1976 & Friuli, Italy & 6.5 & 20.2 & $\mathrm{C}$ & 0.35 & 4.2 & 2.5 \\
\hline 1976 & Friuli, Italy & 6.5 & 20.2 & $\mathrm{C}$ & 0.30 & 4.9 & 2.5 \\
\hline 1994 & Northridge & 6.7 & 26.5 & $\mathrm{D}$ & 0.48 & 5.6 & 2.9 \\
\hline 1989 & Loma Prieta & 6.9 & 31.4 & $\mathrm{D}$ & 0.54 & 6.4 & 1.7 \\
\hline 1989 & Loma Prieta & 6.9 & 94 & $\mathrm{D}$ & 0.27 & 7 & 3.6 \\
\hline 1994 & Northridge & 6.7 & 16.3 & $\mathrm{C}$ & 0.39 & 7.6 & 5.0 \\
\hline 1992 & Landers & 7.3 & 82.1 & $\mathrm{D}$ & 0.31 & 8.2 & 3.8 \\
\hline 1999 & Duzce, Turkey & 7.1 & 41.3 & $\mathrm{D}$ & 0.73 & 8.5 & 2.6 \\
\hline 1994 & Northridge & 6.7 & 13.4 & $\mathrm{D}$ & 0.42 & 9.2 & 6.1 \\
\hline 1979 & Imperial Valley & 6.5 & 12.4 & $\mathrm{D}$ & 0.29 & 10 & 5.7 \\
\hline 1999 & Kocaeli, Turkey & 7.5 & 98.2 & $\mathrm{D}$ & 0.33 & 10.6 & 2.1 \\
\hline 1979 & Imperial Valley & 6.5 & 17.7 & $\mathrm{D}$ & 0.27 & 11 & 5.8 \\
\hline 1994 & Northridge & 6.7 & 25.5 & $\mathrm{D}$ & 0.47 & 11.5 & 5.4 \\
\hline 1995 & Kobe, Japan & 6.9 & 24.2 & $\mathrm{D}$ & 0.34 & 12.9 & 6.5 \\
\hline 1987 & Superstition Hills & 6.5 & 11.2 & $\mathrm{D}$ & 0.45 & 13.8 & 9.8 \\
\hline 1979 & Imperial Valley & 6.5 & 17.6 & $\mathrm{D}$ & 0.17 & 14.6 & 7.2 \\
\hline 1992 & Cape Mendocino & 7 & 22.6 & $\mathrm{D}$ & 0.24 & 15.3 & 4.2 \\
\hline 1987 & Superstition Hills & 6.5 & 35.8 & $\mathrm{D}$ & 0.36 & 16 & 7.0 \\
\hline 1989 & Loma Prieta & 6.9 & 48.2 & $\mathrm{C}$ & 0.37 & 16.4 & 4.6 \\
\hline 1989 & Loma Prieta & 6.9 & 47.9 & $\mathrm{D}$ & 0.25 & 17.4 & 6.4 \\
\hline 1992 & Landers & 7.3 & 86 & $\mathrm{D}$ & 0.15 & 18.8 & 10.9 \\
\hline 1987 & Superstition Hills & 6.5 & 19.5 & $\mathrm{D}$ & 0.16 & 19.6 & 11.8 \\
\hline 1986 & Taiwan SMART & 7.3 & 77.6 & $\mathrm{D}$ & 0.24 & 20.3 & 11.4 \\
\hline 1986 & Hollister & 5.4 & 14.8 & $\mathrm{D}$ & 0.10 & 21.2 & 10.1 \\
\hline 1985 & Valparaiso & 7.8 & 85.7 & $\mathrm{~A} / \mathrm{B}$ & 0.53 & 22.4 & 12.6 \\
\hline 1999 & Chi-Chi, Taiwan & 7.6 & 40.5 & $\mathrm{C}$ & 0.30 & 24.3 & 5.6 \\
\hline 1990 & Manjil, Iran & 7.4 & 84 & $\mathrm{D}$ & 0.13 & 25.7 & 11.1 \\
\hline 1992 & Landers & 7.3 & 13.7 & $\mathrm{C}$ & 0.28 & 26.0 & 21.7 \\
\hline 1992 & Landers & 7.3 & 13.7 & $\mathrm{C}$ & 0.27 & 27.2 & 20.9 \\
\hline 1999 & Hector Mine & 7.1 & 48 & $\mathrm{D}$ & 0.18 & 27.5 & 12.5 \\
\hline 1999 & Chi-Chi, Taiwan & 7.6 & 32 & $\mathrm{D}$ & 0.33 & 28.3 & 13.3 \\
\hline 1990 & Manjil, Iran & 7.3 & 40.4 & $\mathrm{C}$ & 0.51 & 28.9 & 7.5 \\
\hline 1992 & Landers & 7.3 & 27.3 & $\mathrm{D}$ & 0.17 & 31.8 & 20.9 \\
\hline 1992 & Landers & 7.3 & 21.3 & $\mathrm{D}$ & 0.13 & 32.1 & 22.8 \\
\hline 1985 & Valparaiso & 7.8 & 115 & $\mathrm{D} / \mathrm{E}$ & 0.43 & 33.7 & 20.4 \\
\hline 1999 & Chi-Chi, Taiwan & 7.6 & 28.4 & $\mathrm{D}$ & 0.18 & 34.6 & 20.5 \\
\hline 1979 & St Elias, Alaska & 7.5 & 74.8 & $\mathrm{D}$ & 0.09 & 35.5 & 18.2 \\
\hline 1992 & Landers & 7.3 & 32.3 & $\mathrm{D}$ & 0.11 & 36.3 & 23.6 \\
\hline 1992 & Landers & 7.3 & 32.3 & $\mathrm{D}$ & 0.10 & 37 & 25.1 \\
\hline 1999 & Chi-Chi, Taiwan & 7.6 & 33.8 & $\mathrm{D}$ & 0.12 & 38.7 & 28.6 \\
\hline 2002 & CA/Baja Border & 5.3 & 42.2 & $\mathrm{D}$ & 0.04 & 39.9 & 11.6 \\
\hline 1985 & Valparaiso & 7.8 & 74.3 & $\mathrm{~A} / \mathrm{B}$ & 0.31 & 40.4 & 20.3 \\
\hline 1985 & Valparaiso & 7.8 & 65 & Not available & 0.68 & 42.6 & 30.4 \\
\hline 2002 & CA/Baja Border & 5.3 & 42.2 & $\mathrm{D}$ & 0.08 & 43.5 & 13.0 \\
\hline 1999 & Chi-Chi, Taiwan & 7.6 & 41.4 & $\mathrm{D}$ & 0.19 & 45.9 & 26.1 \\
\hline 1985 & Valparaiso & 7.8 & 25.4 & Not available & 0.30 & 48.4 & 31.3 \\
\hline 1985 & Valparaiso & 7.8 & 25.4 & Not available & 0.16 & 49.9 & 37.1 \\
\hline 2007 & $\mathrm{KM}$, Indonesia & 7.9 & 164.6 & Not available & 0.13 & 50.3 & 35.5 \\
\hline 1979 & Imperial Valley & 6.5 & 33.7 & $\mathrm{D}$ & 0.35 & 50.3 & 22.4 \\
\hline 1979 & Imperial Valley & 6.5 & 33.7 & $\mathrm{D}$ & 0.22 & 51 & 24.2 \\
\hline 2007 & $\mathrm{KM}$, Indonesia & 7.9 & 164.6 & Not available & 0.09 & 52.9 & 36.0 \\
\hline 1985 & Valparaiso & 7.9 & 25.3 & Not available & 0.20 & 55.9 & 28.2 \\
\hline 1985 & Valparaiso & 7.9 & 25.3 & Not available & 0.23 & 56.3 & 37.0 \\
\hline 1995 & Kobe, Japan & 6.9 & 47.5 & $\mathrm{D}$ & 0.08 & 58.3 & 12.1 \\
\hline 1999 & Chi-Chi, Taiwan & 7.6 & 69.3 & $\mathrm{D}$ & 0.12 & 61.4 & 27.8 \\
\hline 1995 & Kobe, Japan & 6.9 & 47.5 & $\mathrm{D}$ & 0.06 & 70.6 & 21.2 \\
\hline 2002 & Denali, Alaska & 7.9 & 189.6 & $\mathrm{C}$ & 0.08 & 73.6 & 51.5 \\
\hline 2002 & Denali, Alaska & 7.9 & 189.6 & $\mathrm{C}$ & 0.07 & 76.6 & 48.7 \\
\hline 1999 & Chi-Chi, Taiwan & 7.6 & 71.6 & $\mathrm{D}$ & 0.10 & 76.9 & 29.5 \\
\hline 1999 & Chi-Chi, Taiwan & 7.6 & 71.6 & $\mathrm{D}$ & 0.10 & 80.1 & 35.7 \\
\hline 2002 & Denali, Alaska & 7.9 & 148.1 & $\mathrm{D}$ & 0.04 & 94.4 & 25.7 \\
\hline 2002 & Denali, Alaska & 7.9 & 93.4 & $\mathrm{C}$ & 0.07 & 97.4 & 39.3 \\
\hline 2002 & Denali, Alaska & 7.9 & 93.4 & $\mathrm{C}$ & 0.06 & 98.7 & 42.3 \\
\hline 2002 & Denali, Alaska & 7.9 & 150 & $\mathrm{C}$ & 0.07 & 104.2 & 27.8 \\
\hline 2002 & Denali, Alaska & 7.9 & 296.4 & $\mathrm{D}$ & 0.02 & 116.1 & 61.1 \\
\hline $\mathrm{n} / \mathrm{a}$ & Cascadia & 9.2 & 446.8 & $\mathrm{~B} / \mathrm{C}$ & 0.16 & 132.3 & 59.5 \\
\hline $\mathrm{n} / \mathrm{a}$ & Cascadia & 9.2 & 446.8 & $\mathrm{~B} / \mathrm{C}$ & 0.13 & 137.2 & 61.8 \\
\hline $\mathrm{n} / \mathrm{a}$ & Cascadia & 9.2 & 481.3 & $\mathrm{~B} / \mathrm{C}$ & 0.05 & 162.2 & 94.2 \\
\hline $\mathrm{n} / \mathrm{a}$ & Cascadia & 9.2 & 481.3 & $\mathrm{D} / \mathrm{E}$ & 0.13 & 188 & 116.4 \\
\hline $\mathrm{n} / \mathrm{a}$ & Cascadia & 9.2 & 446.8 & $\mathrm{D} / \mathrm{E}$ & 0.16 & 196.7 & 142.0 \\
\hline $\mathrm{n} / \mathrm{a}$ & Cascadia & 9.2 & 481.3 & $\mathrm{D} / \mathrm{E}$ & 0.14 & 206 & 116.3 \\
\hline $\mathrm{n} / \mathrm{a}$ & Cascadia & 9.2 & 446.8 & $\mathrm{D} / \mathrm{E}$ & 0.18 & 230.1 & 147.1 \\
\hline $\mathrm{n} / \mathrm{a}$ & Cascadia & 9.2 & 481.3 & $\mathrm{~B} / \mathrm{C}$ & 0.04 & 271.3 & 116.3 \\
\hline
\end{tabular}

Table 1: Short and long significant duration ground motion dataset. 


\subsection{IM efficiency testing}

Figure 2 illustrates for the testbed application and the four considered IMs, the "maximum over height" dispersions of the IM capacities $\beta_{\text {IM }}$ given IDR or PFA. The range of both EDP types has been selected to span from the elastic up to the inelastic level of structural response. The maximum signifies the worst performance along the height of the building. The "average $\beta_{\mathrm{IM}}$ over height" of the building is also plotted to indicate the average efficiency of each IM at each level of deformation/response.

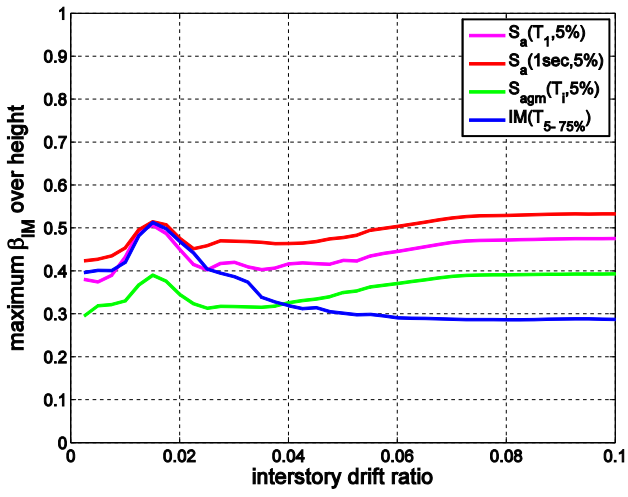

(a) maximum dispersion of IDR given IM

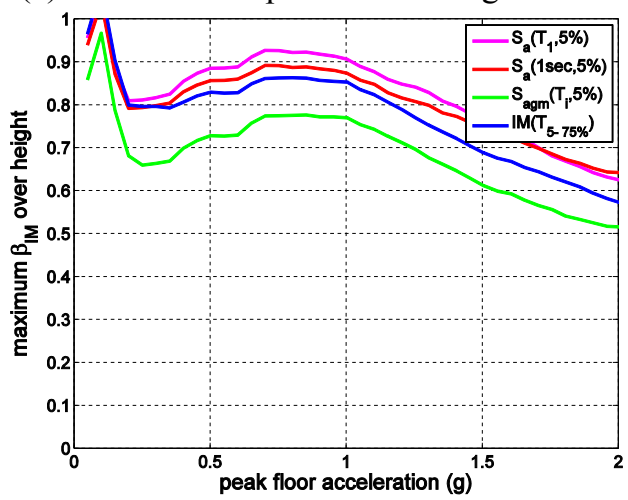

(c) maximum dispersion of PFA given IM

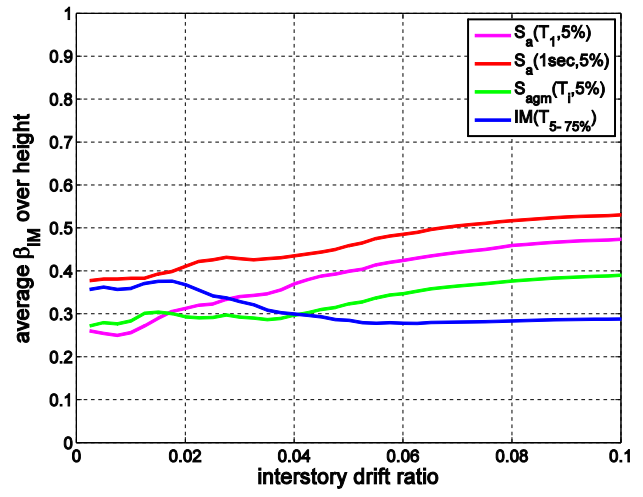

(b) average dispersion of IDR given IM

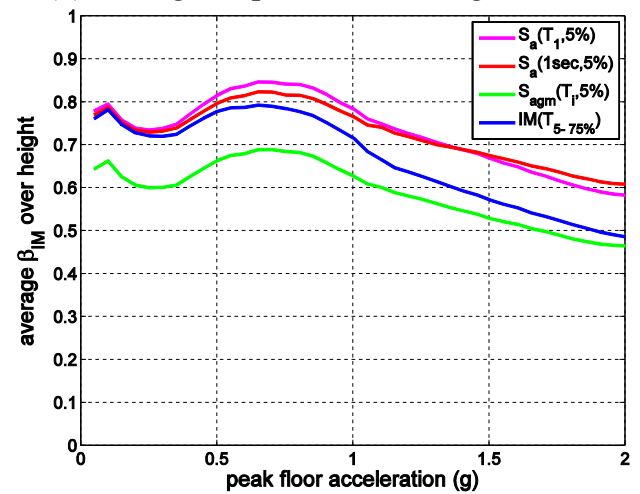

(d) average dispersion of PFA given IM

Figure 2: Maximum and average dispersions of the IM for given values of IDR and PFA response of the steel MRF considering three IMs.

Considering the aforementioned results some characteristic features appear. Quite notably, the IM ranking is not clear across the entire range of IDR values (Figures $2 a$ and $2 b$ ). In particular, $S_{a}\left(T_{1}\right)$ shows the best performance in the early elastic region, $S_{a g m}\left(T_{i}\right)$ takes advantage in the post-yield region where the spread of inelasticity results in elongated periods and finally the newly proposed $I M\left(T_{5-75 \%}\right)$, which combines significant duration with $S_{a g m}\left(T_{i}\right)$, performs best in the post-capping range, which at a global level denotes the range from the maximum base shear to collapse. Regarding the IM ranking for the PFAs (Figures 2c and 2d) the dispersions reported for all four IMs are significantly higher than those reported for the IDRs, while the best performing IM is the $S_{a g m}\left(T_{i}\right)$. Interestingly though, regardless of the IM, there is significant difficulty in capturing the complex interaction of modes that affects the PFA response and the use of all four IMs was proven to be relatively expensive, i.e. more ground motion records are needed to provide relatively stable PFA dispersion estimates.

Evidently, there does not seem to be a perfect single IM that is optimal for all EDPs and ranges. Hence, when considering both accelerations and drifts in loss assessment studies, 
where the majority of the damage occurs prior to the global collapse in modern buildings, then $S_{\text {agm }}\left(T_{i}\right)$ seems to be a reasonable choice. By contrast, in the case of collapse vulnerability studies, which are performed on a drift basis considering the responses beyond the capping point, then the significant duration was proven to affect the collapse capacity and hence its inclusion in a scalar IM, such as the $I M\left(T_{5-75 \%}\right)$, results in an improved efficiency in the region of interest.

\subsection{IM sufficiency testing}

The sufficiency of the considered IMs is tested against the significant duration $T_{5-75 \%}$. Given that we are only interested in demonstrating the sufficiency of $\operatorname{IM}\left(T_{5-75 \%}\right)$ for use with collapse assessment studies in view of the efficiency findings, the results will be presented only for the testing performed on a drift basis. To accomplish this, a linear regression analysis between $\ln (\mathrm{IM} \mid \mathrm{EDP})$, i.e. the logarithm of IM capacity values for a given value of any of the drift related EDPs, and the $T_{5-75 \%}$ value of the record was undertaken as follows,

$$
\ln (I M \mid E D P)=a+b T_{5-75 \%}
$$

The logarithm of IM|EDP was adopted, since the latter is generally lognormally distributed for the considered range of IMs and EDPs [25]. The proposed methodology for checking sufficiency is advantageous, since it avoids the problems associated with performing the regression analysis over the entire EDP range, an approach that obviously becomes problematic close to collapse (defined here as dynamic instability), but has been found considerable use in previous studies (e.g.[3], [24]). On the other hand, the proposed process reduces the number of data points available for fitting Equation 4 since the fitting process takes place at distinct EDP levels, thus requiring a large number of records for sound interpretation. The results of such tests will be summarized by the following quantities:

(a) The ratio of the number of EDPs for which $T_{5-75 \%}$ is significant over the total number of EDPs considered,

(b) The average $p$-value for significance of the $T_{5-75 \%}$ regression,

(c) The average dispersion $\beta$ explained by $T_{5-75 \%}$,

(d) The average $T_{5-75 \%}$ regression coefficient.

Figure 3 illustrates the sufficiency testing against $T_{5-75 \%}$. Clearly, across the examined IDR range there is significant scatter. By inspecting Figure 3a we can say that as the structure approaches its collapse state, the sole IM that remains sufficient against $T_{5-75 \%}$ is the one accounting for the significant duration, i.e. the $I M\left(T_{5-75 \%}\right)$, whereas the remaining three show a significant dependence on $T_{5-75 \%}$ which escalates gradually and becomes absolute for IDR values greater than $4 \%$. The aforementioned finding is further supported by inspecting Figure $3 \mathrm{~b}$, where for IDR values beyond $4 \%$, the $S_{a}\left(T_{1}\right), S_{a}(1 \mathrm{sec})$ and $S_{a g m}\left(T_{i}\right)$ exhibit quite a strong dependence on $T_{5-75 \%}$ that is manifested by the small $\mathrm{p}$-values $(\mathrm{p}<0.05)$ for IDRs $>4 \%$. With respect to the dispersion explained by $T_{5-75 \%}$ (see Figure $3 \mathrm{c}$ ), this was found to be very low for the newly proposed $I M\left(T_{5-75 \%}\right)$ when the structure is well in the inelastic range, whereas the same quantity for the remaining IMs may reach $\sim 0.1-0.15$ close to collapse. This observation demonstrates that adding $T_{5-75 \%}$ in the definition of the IMs can offer a significant reduction in the overall collapse dispersion. Finally, Figure $3 \mathrm{~d}$ illustrates the average regression coefficient $b$. The maximum reported values for $b$ in the close to collapse response range are in the order of $7-8.5 \cdot 10^{-3}$. Considering that for the given set of records $T_{5-75 \%}$ ranges from $\sim 0.3-147 \mathrm{~s}$ (with a mean of $\sim 27 \mathrm{~s}$ ) a value of $b=8.5 \cdot 10^{-3}$ indicates a maximum change due to $T_{5-75 \%}$ for the 
worst performing IM by a factor of $\exp (\mathrm{b} \cdot(147-27))=2.8$. The magnitude of this factor denotes a significant local bias close to the collapse range.

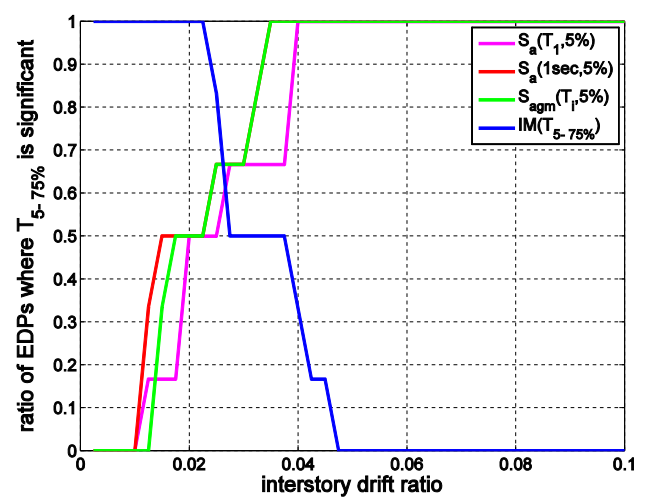

(a) ratio of IDR for which $T_{5-75 \%}$ is significant

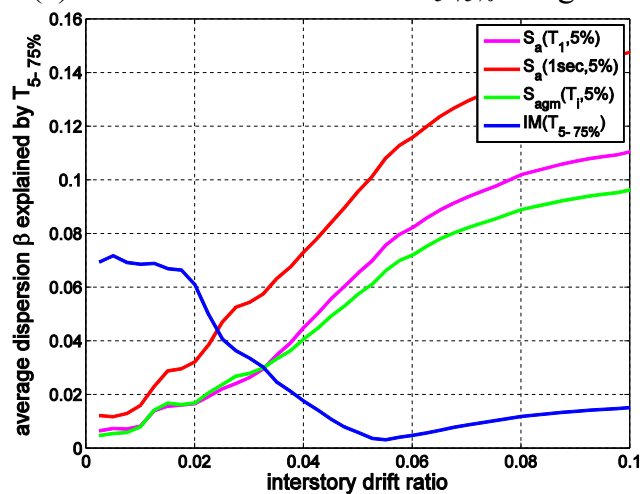

(c) average dispersion $\beta$ explained by $T_{5-75 \%}$

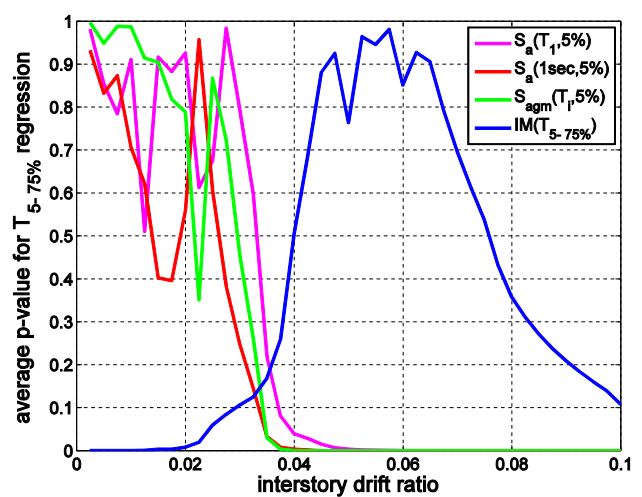

(b) average $p$-value for $T_{5-75 \%}$ regression

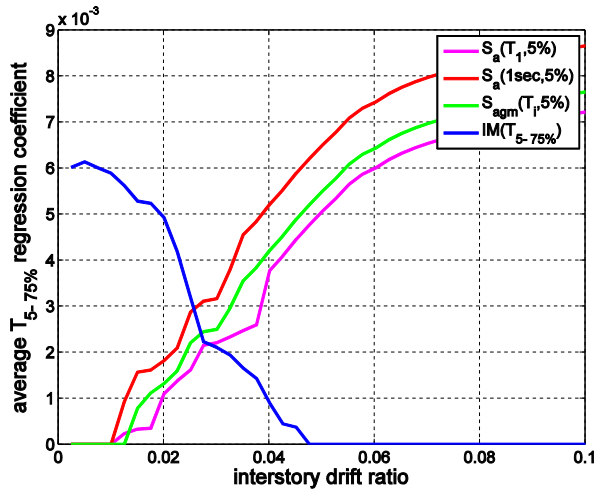

(d) average $T_{5-75 \%}$ regression coefficient

Figure 3: Variables for testing the sufficiency of the IMs against $T_{5-75 \%}$ across the IDR range.

\section{CONCLUSIONS}

The efficiency and sufficiency of a scalar IM for use in vulnerability studies that is based on the geometric mean spectral acceleration concept combined with the significant duration was explored in this study. It has been demonstrated that significant duration is closely correlated to the collapse capacity and hence should not be disregarded in collapse vulnerability assessment studies. By contrast, in loss assessment studies of modern structures, where the majority of the losses occur at drift and acceleration levels well before the global instability state, the adoption of a geometric mean of spectral accelerations across the entire range of interest seems to be a reasonable choice while its further refinement with adding the significant duration to the IM definition does not add to the accuracy. The aforementioned findings were obtained on the basis of a capacity-designed steel MRF and hence their projection to other cases should be done with caution.

\section{ACKNOWLEDGEMENT}

Financial support was provided by the GEM Foundation through the GEM Vulnerability Consortium, the EU Research Executive Agency via the Marie Curie Continuing Integration Grant No. PCIG09-GA-2011-293855, and Greece and the European Union (European Social Fund) through the Operational Program "Human Resources Development" of the National Strategic Framework (NSRF) 2007-2013. The authors would also like to thank Prof. Abbie B. Liel and Dr. Meera Raghunandan for kindly providing the ground motion record set. 


\section{REFERENCES}

[1] C.A. Cornell, Engineering seismic risk analysis. Bulletin of the Seismological Society of America, 58(5), 1583-1606, 1968.

[2] N. Luco, C.A. Cornell, Structure-specific scalar intensity measures for near-source and ordinary earthquake ground motions. Earthquake Spectra, 23(2), 357-392, 2007.

[3] J.W. Baker, C.A. Cornell, A vector-valued ground motion intensity measure consisting of spectral acceleration and epsilon. Earthquake Engineering and Structural Dynamics, 34(10), 1193-1217, 2005.

[4] P.P. Cordova, G.G. Deierlein, S.S. Mehanny, C.A. Cornell, Development of a twoparameter seismic intensity measure and probabilistic assessment procedure. Proceedings of the $2^{\text {nd }}$ US-Japan Workshop on Performance-based Earthquake Engineering Methodology for RC Building Structures, Sapporo, Hokkaido, 2000.

[5] S. Tsantaki, C. Adam, Collapse capacity spectra based on an improved intensity measure. Proceedings of the $4^{\text {th }}$ ECCOMAS Thematic Conference on Computational Methods in Structural Dynamics and Earthquake Engineering (COMPDYN 2013), Kos, Greece, 2013.

[6] E. Bojorquez, I. Iervolino, Spectral shape proxies and nonlinear structural response. Soil Dynamics and Earthquake Engineering, 31(7), 996-1008, 2011.

[7] A.K. Kazantzi, D. Vamvatsikos, Analytical vulnerability assessment of modern highrise RC moment-resisting frame buildings in the Western USA for the Global Earthquake Model. Proceedings of the $2^{\text {nd }}$ European Conference on Earthquake Engineering and Seismology, Istanbul, Turkey, 2014.

[8] A.K. Kazantzi, D. Vamvatsikos, Intensity measure selection for vulnerability studies of building classes. Earthquake Engineering and Structural Dynamics, to appear.

[9] M. Raghunandan, A.B. Liel, Effect of ground motion duration on earthquake-induced structural collapse. Structural Safety, 41, 119-133, 2013.

[10] A.K. Kazantzi, D. Vamvatsikos, D.G. Lignos, Seismic performance of a steel momentresisting frame subject to strength and ductility uncertainty. Engineering Structures, 78, 69-77, 2014.

[11] E.I. Katsanos, A.G. Sextos, G.D. Manolis, Selection of earthquake ground motion records: A state-of-the-art review from a structural engineering perspective. Soil Dynamics and Earthquake Engineering, 30, 157-169, 2010.

[12] J. Hancock, J.J. Bommer, Using spectral matched records to explore the influence of strong-motion duration on inelastic structural response. Soil Dynamics and Earthquake Engineering, 27, 291-299, 2007.

[13] A. Arias, A measure of earthquake intensity. Cambridge, MA, 1970.

[14] J.W. Baker, C.A. Cornell, Which spectral acceleration are you using? Earthquake Spectra, 22(2), 293-312, 2006.

[15] FEMA 350, Recommended seismic design criteria for new steel moment frame buildings, prepared by Federal Emergency Management Agency, Washington, DC, 2000.

[16] F. McKenna, G. Fenves, B. Jeremic, M. Scott, Open system for earthquake engineering simulation, $2000<\mathrm{http}$ ://opensees.berkeley.edu $>$. 
[17] D.G. Lignos, H. Krawinkler, Deterioration modeling of steel components in support of collapse prediction of steel moment frames under earthquake loading. Journal of Structural Engineering (ASCE), 137(11):1291-302, 2011.

[18] D.G. Lignos, H. Krawinkler, A.S. Whittaker, Prediction and validation of sidesway collapse of two scale models of a 4-story steel moment frame. Earthquake Engineering and Structural Dynamics, 40(7), 807-825, 2011.

[19] D. Vamvatsikos, C.A. Cornell, Incremental dynamic analysis. Earthquake Engineering and Structural Dynamics, 31(3), 491-514, 2002.

[20] PEER, PEER NGA Database, Pacific Earthquake Engineering Research Center, University of California, Berkeley, California, $2006<\mathrm{http}$ ://peer.berkeley.edu/nga/ $>$.

[21] J. Yang, Nonlinear responses of high-rise buildings in giant subduction earthquakes, Ph.D. Thesis, California Institute of Technology, 2009.

[22] COSMOS, COSMOS Virtual Data Center, $2011<\mathrm{http}$ ://db.cosmos-eq.org/>.

[23] United States Geological Survey (USGS), National Strong-Motion Project, 2012 $<$ http:// nsmp.wr.usgs.gov/>.

[24] P. Tothong, N. Luco, Probabilistic seismic demand analysis using advanced ground motion intensity measures. Earthquake Engineering and Structural Dynamics, 36(13), 1837-1860, 2007.

[25] NIST, Evaluation of the FEMA P-695 methodology for quantification of building seismic performance factors, Report No. NIST GCR 10-917-8. Prepared for the US National Institute of Standards and Technology by the NEHRP Consultants Joint Venture, Gaithersburg, MD, 2010. 